\title{
Computational psycholinguistic analysis and its application in psychological assessment of college students
}

Dalibor Kučera, Jana Marie Havigerová

Abstract: The paper deals with the issue of computational psycholinguistic analysis (CPA) and its experimental application in basic psychological and pedagogical assessment. CPA is a new method which may potentially provide interesting, psychologically relevant information about the author of a particular text, regardless of the text's factual (semantic) content and without the need to obtain additional materials. As part of our QPA-FPT research we studied the link between the linguistic form of a text by Czech college students and their personality characteristics obtained from a psychodiagnostic test battery. The article also discusses the basis of the method, opportunities for practical application and potential use within psychological and pedagogical disciplines.

Key words: psycholinguistics, computational, analysis, assessment, psychodiagnostics, Czech.

\section{Introduction}

In daily life, and educational practice in particular, we generally deal with a substantial amount of text data - homework assignments, seminar papers, or ordinary communication via email and social networks. Recipients generally perceive texts purely semantically or in terms of formality. The semantic content of communication, that is, what the author aims to share with the recipient, is crucial for text interpretation. Nevertheless, there is another layer 
of text that can be studied and interpreted - its formal linguistic realization, that is, its morphology and/or syntax. This latter is not usually linked to the factual semantics of the text, but rather to its author and his or her personality, opinions and attitudes. The way people use words, as a marker of social and personality processes, is not a new concept. It is one that has been considered by many psychologists, linguists, anthropologists, and philosophers (Hamilton, 1957, p. 153) and it has been scientifically studied by many authors (for example, Freud, 1901) since the beginning of the 20th century. More than 100 years later, the belief that such a link exists still holds much appeal. There is also a tradition, found in the work of scholars such as Austin (1975), Scherer and Giles (1979), and Searle (1969), that analyzes the way we speak and act in order to relate our experiences to other people in social exchanges. If the ideas of these authors are correct, we could learn much more from a text; that is, not just what the content is, but we could also gain greater knowledge and understanding of the author. This is of crucial importance for educational and psychological practice as well as for assessment and evaluation. If teachers are able to gain an unobtrusive insight into a student's personality, it may enable them to understand the student better and thus adapt their teaching and individualize their approach to the student. Developing a method that results in the practical application of psycholinguistic analysis may, furthermore, enrich and interconnect the fields of pedagogy and psychology.

\section{Computational Psycholinguistic Analysis of Texts}

Current approaches dealing with the psychological aspects of texts are most often found in psycholinguistics, a science that was established at the beginning of the 1950s, drawing together psychology and linguistics. This discipline covers a wide spectrum of issues, such as speech production and reception, mental structures, the relationship between language competence and performance, the mental representation of linguistic constructs, the relationship between language and cognitive processes, language acquisition, and sometimes also the biological basis of language, non-verbal communication (Nebeská, 1992, p. 8). Despite the interest in and attention paid to the study of texts, findings relating to psychological aspects of verbal communication are still often partial and ambiguous (Aaronson $\&$ Rieber, 2013). The reasons for these difficulties are more or less obvious - verbal communication is very complex and there is an enormous number of variables, styles and singularities among its users, the communicators. This has led many psycholinguistic researchers to focus more on language acquisition, production, comprehension, and the links to brain activity, rather than study text as a marker of personality and social processes (Pennebaker \& Graybeal, 2001, p. 91). 
Despite these limitations, there are a number of studies on verbal communication that deal with some innovative aspects, for instance with a broad spectrum of communication variables, particularly their relationship to the key characteristics of the communicator. In addition to general psychological applications, there are a number of clinical applications, for instance, methods for establishing medical and psychiatric diagnoses. Some studies indicate that text analysis can help to diagnose somatization disorders (Oxman, Rosenberg et al. 1988), schizophrenia (Taylor, Reed, \& Berenbaum, 1994), suicidal tendencies (Thomas \& Duszynski, 1985) and depression (Schnurr, Rosenberg, \& Oxman, 1992). One group of researchers demonstrated that health improvement can be predicted by analyzing writing style (formal parameters and particularly pronouns). "The text analyses demonstrated that changes in writing styles were consistently associated with better health, whereas similarity in the content of writing was unrelated to health outcome." (Campbell \& Pennebaker, 2003, p. 64) A different approach looks at the level of social processes, for links between the communicator's communication strategy and relational strategy. Cheng used this approach and found, for example, that "different relational strategies are linked to a given personality trait (which) predisposes the person to relate to another in a certain way" (Cheng, 2011, p. 2). Many studies have focused on the effect of demographic variables (for instance sex or age) as well. "People exhibited remarkably consistent changes in their linguistic styles. With increasing age, individuals used more positive emotion words, fewer negative emotion words, fewer first person singular self-references, more future tense, and fewer past tense verbs." (Pennebaker et al., 2003, p. 556)

With the appearance of the internet, new opportunities for studying linguistic phenomena have opened up. There are large amounts of data to be found on web pages, blogs and chats, and in email communication. Moreover, all major newspapers, magazines, periodicals, and journals are now available online and maintain comprehensive electronic archives (Mehl, 2006, p. 153). Given this, quantitative text analysis (QTA) provides the researcher with a wide range of possibilities for describing and statistically processing text samples (Pennebaker et al., 2003, p. 549). Quantitative text analysis is "any systematic reduction of a flow of text (or other symbols) to a standard set of statistically manipulable symbols representing the presence, the intensity, or the frequency of some characteristics relevant to social science" (Shapiro \& Markoff, 1997, p. 14). As a scientific method, text analysis was first used during World War II, to analyze the content of Nazi propaganda (Krippendorff, 1980). Since the 1960s, a number of techniques have been used in QTA. They differ in many aspects and strategies, for instance, coding (human judges or computerized word count strategies) and the linguistic parameters 
they examined. It is beyond the scope of this introduction to summarize all the strategies available to researchers. Since the 1970s, personal computers and the digitalization of data have led to rapid developments in computational text analysis (CTA) using advanced text-mining and text-analyzing applications. Word search and processing engines have become very sophisticated in the last decade and at present, they are used across the internet. The automatic linguistic analysis of texts has also made significant progress. Automatic lemmatization (determination of basic, "dictionary" word-form) and automatic part-of-speech tagging have achieved considerable reliability, using stochastic and rule-based methods (for example, Garside \& Smith, 1997). They are often based on neural networks, which effectively extract and classify relationships among words and phrases.

Using these methods, a text can be successfully computerized and the collected data analysed. Follow-up work with the data opens up further possibilities for text analysis, for example in the social sciences, particularly psychology. One such method is referred to as computational psycholinguistic analysis (CPA). The research related to this article uses CPA to demonstrate its potential in assessing the basic personality of the author of a text. This field has already been investigated by a number of scientists. Sanford (1942) argued that verbal behavior was a powerful marker of personality. Some psychologists have followed up on this observation (examples include Furnham, 1990; Scherer \& Giles, 1979; Weintraub, 1989). Like non-verbal forms of social behavior, verbal forms of social behavior, such as speech acts, are a means of achieving goals, and therefore comply with the definition of a particular trait (Cheng, 2011, p. 10). The research includes many interesting findings relating to specific personality traits. One study used traditional Big Five personality questionnaires (Pennebaker \& King 1999) and found "modest but reliable effects of personality on word choice" (Pennebaker et al., 2003, p. 558), for instance neuroticism was characterized by more frequent use of the first person singular and negative emotion words. Moreover, interpersonal functioning is probably connected to how people verbally express themselves. Usually, when two people interact, they communicate using words. Cegala (1989) found that people highly involved in interpersonal interactions use a greater number of certainty expressions, more attributes of verbal immediacy, and more relational pronouns ("we", "us", “our"), while Pennebaker \& Davis (2006) found that a person who uses words referring to the self (e.g. "I") less is probably a higher status communicator. We can also highlight research dealing with personality disorders and malfunctions. Rude et al. (2004) found depression to be related to an elevated use of first person singular pronouns and a lack of second person and third person pronouns. What is interesting is that the effect was pro- 
duced by greater use of the word "I" only. There was no change in the use of the pronouns "me", "my", and "mine" between the two groups (Pennebaker et al., 2003, p. 560).

To sum up, words are an important feature of social, personality, clinical and cognitive functioning. It is time to start taking them more seriously and use them as an instrument to bridge the gap between personality and behavior, and to make use of this kind of analysis in areas that might utilize its diagnostic potential, for instance, psychology or pedagogy.

\section{Methods and Research Design}

As has already been mentioned, there are many ways to computerize nonsemantic (formal) characteristics of texts for further use (for example, psychological). They differ in the method used, the computational strategy, and, of course, the language of the text in question. In the previous section we introduced some promising perspectives in the current psycholinguistic research based on QTA and formal parameters of text (FPT) description. These mechanisms were tested on English-speaking populations. However, Czech differs from English in a number of aspects, such as inflection (Czech being highly inflected while English is only weakly inflected; affixes indicate grammatical functions), lexicology (for instance, the much more extensive range of diminutives in Czech compared to English), or syntax (for example, English word order is more fixed) (Hornová, 2003). That is why it is necessary to perform the research on the Czech population in relation to Czech.

Drawing on the research results of relevant studies conducted in other countries, we designed a Quantitative Psycholinguistic Analysis of Formal Parameters of Czech Text (QPA-FPT) research project. The research has been ongoing since April 2013. It is hoped the project will demonstrate which communication styles people select according to their personality features. The aim of the research is to find specific correlations between formal (non-semantic) characteristics of a Czech text and the personality traits of its author.

The research design combines two techniques:

- Firstly, it makes use of an automatic system of linguistic disambiguation and position tagging, which provides detailed data on the formal characteristics of the text, particularly its morphology (for example, parts of speech, gender, number (singular/plural), case, person, tense and negation).

- Secondly, it utilizes quantitative psychological assessment which enables the researcher to describe the author's personal and interpersonal characteristics. 


\section{Research Sample and Text Categories}

There are 174 subjects who are all teacher training students, either full or part-time, at the Faculty of Education, University of South Bohemia, in the Czech Republic. The sample, obtained through occasional sampling, includes 133 women and 41 men, with an average age of 28. The participants were asked to participate voluntarily in the research by taking part in a psychodiagnostic exercise during psychology seminars. The subjects were subsequently asked to submit a qualified consent form and basic personal data in addition to completing a psychodiagnostic test battery, writing and electronically submitting four specific types of text (see below). Once all the material had been collected and the data evaluated, all the participants were provided with their test results and additional detailed comments.

Various types of text were used for the research purposes. Four types were produced involving specific scenarios with a word limit of 200-250 words per text. The scenarios involve two pairs of modalities. The first pair, "dominant/ submissive", reflects the writer's personal relation to the addressee, that is whether he or she is in a more or less self-confident, assertive and firm position. The other pair, "formal/informal", is connected to certain social, that is, stylistic requirements, typical of specific text types. It is important to note that these four modalities are more a theoretical/artificial concept, which has been used to highlight differences between given scenarios and to demonstrate the required stylistic diversity of texts (the factual semantic representation of the communication could nevertheless vary more and could show the overlap between the modalities on an individual basis for instance).

The following scenarios were developed:

- TXT1: motivation letter (submissive/formal);

- TXT2: postcard from holiday (dominant/informal);

- TXT3: letter of complaint(dominant/formal);

- TXT4: letter of apology (submissive/informal).

\section{Analysis of Formal Parameters of Text}

Formal (non-semantic) QTA classification relies on successfully defining the morphological category values for every word which fits the particular context and the definition of its generic form (lemma - lemmatization process).

This type of analysis is conducted using a set of software applications, which "tag" the text automatically, particularly stochastic applications and applications based on linguistic rules (Petkevič, 2006; Spoustová, 2008; Hajič, 2004). All the texts in the research were lemmatized and morphologically tagged in this way. 
First of all automatic language tagging was performed using morphological analysis (Hajič, 2004), which ascribed all possible interpretations to every word. After that all the interpretations were analyzed using disambiguation (a process for resolving conflicts that arise when a single term is ambiguous); "rule-based" disambiguation (Petkevič, 2006) and stochastic disambiguation MorCE (Votrubec, 2006) were used. All these machine-controlled systems effectively determined one specific interpretation for every word within a sentence and described it in 13 morphological categories of each word (part of speech; detailed part of speech; gender; number (sing./ plur.); case; gender of the possessive form; possessor's number (singular/ plural possessive); person; tense; comparative/superlative; negation; voice; and word variation, style, register and special usage) (for further reading see Spoustová, 2008; Hajič, 2004). The morphological analysis was carried out by a team at the Institute of Theoretical and Computational Linguistics, Faculty of Arts, Charles University.

Table 1

Sample of transcription analysis

\begin{tabular}{|l|l|}
\hline Sentence & „Pojd’te s námi do ZOO.“ (lit. trans. “Come with us to the zoo.”) \\
\hline Categories & $\begin{array}{l}\text { Pojd’te (jit Vi-P--2--A--1) s (s RR--7--------) námi (my PP-P7--1-------) } \\
\text { do (do RR--2----------) ZOO (ZOO NNFS2-----A----) . (. Z:-------------) }\end{array}$ \\
\hline
\end{tabular}

The sample (table 1) shows the analysis of a sentence, where each item (word or punctuation mark) is assigned information on its base form, and this is followed by 15 positions indicating the grammar category (positions 13 and 14 are not used). The raw data analysis was subsequently converted into statistical data representing the proportional occurrence of a specific category in the texts.

\section{Psychodiagnostic Tests}

All the subjects completed a Czech version of the following psychodiagnostic tests:

- TCI-R (Temperament and Character Inventory Revised; Cloninger, 2008) - a seven-dimensional personality screening questionnaire; based on the psychobiological theory of personality; 240 self-report items, 30 subscales in four temperament dimensions: Novelty Seeking, Harm Avoidance, Reward Dependence, Persistence; and three character dimensions: Self-Directedness, Cooperativeness, Self-transcendence. 
- STAI X-2 (State-Trait Anxiety Inventory; Spielberger, Gorsuch, \& Lushene, 1970) - psychological inventory based on a 4-point Likert scale; 20 questions on a self-report basis; focused on trait anxiety, that is, anxiety as a personality characteristic.

- BIDR6 (Balanced Inventory of Desirable Responding; Paulhus, 1988) psychological inventory; 40 questions on a self-report basis; measures two constructs: self-deceptive positivity (the tendency to give self-reports that are honest but positively biased) and impression management (deliberate self-presentation to an audience).

Both TCI-R and STAI X-2 questionnaires were adapted for the Czech population (Preiss, M., Kuchařová, J., Novák, T., \& Štěpánková, H., 2007; Müllner, J., Ruisel, I., \& Farkaš, G, 1980), the BIDR6 is a standardized test, but its test norms only include the American population (Figurová, 2007). Results from the BIDR6 test are not included in the following section.

\section{Preliminary Findings}

Various data were collected and analyzed, such as the length of the text, the syntax, word order, morphology and frequency of the individual parts of speech. The data were then compared with biographical data relating to the subject and with his/her test results. The aim was to find possible relations and correlations.

As the research (data analysis) is currently in progress, only the preliminary findings can be presented. So far, the characteristics describing the proportional occurrence of selected linguistic categories in a given text have been processed; that is the proportion of pronouns, singular/plural, person (first, second and third), tense (past tense, present tense, future tense), and negation using negative prefixes.

The full results will be published and discussed once the research has been completed. The preliminary results, nevertheless, indicate the following findings:

1. Various text types (TXT1-TXT4) display fairly diverse formal (linguistic) characteristics. Thus, great stylistic consistency across different text types was not found when morphology was studied (for example one author predominantly used the first person plural in one type of text while using the third person singular in another). An average correlation between the same parameters (for example, the occurrence of a specific category of person) of different text types was substantially weak and below borderline statistical significance $(r=-0.019, p=0.445)$. Thus, it would 
seem that only one particular type of text type should be used (for instance, formal submissive or TXT1), that is, not all text types should be used at the same time.

2. Drawing on the previous point, it is clear that none of the personality traits has significantly correlated with a particular (morphological) text parameter across all the texts. So far, it is possible to conclude a correlation between a particular text type and a particular personality trait (for example, the Social Intolerance trait only correlates with linguistic negation in text TXT4, which is a letter of apology).

3. Significant correlations among particular text parameters and specific personality traits in the whole sample had fairly weak values (ca. $r= \pm$ $0.2-0.25)$. The male sample had higher correlations, that is, moderate correlation (ca. $r= \pm 0.35-0.5$ ).

4. In terms of the diagnostics of personality characteristics, TXT1 (motivation letter) has proved to have the greatest diagnostic potential, throughout the whole sample (both men and women). The most significantly correlating item from the linguistic characteristics perspective is plural; for example, correlation with Novelty Seeking, $r=-0.23$, and with its subscales Impulsiveness, $r=-0.26$ and Extravagance, $r=-0.22)$. The most significantly correlating personality traits item is Novelty Seeking and its subscales; for instance, Extravagance also correlated with the number of pronouns, $r=0.23$.

To sum up, the research results have proved to be of great interest and, in many ways, quite surprising. From this point of view, the diversity in using formal (that is, morphological) characteristics within various types of text was most surprising (compared to Pennebaker \& King, 1999, p. 1309 for instance). These results can be used as a starting point for follow-up studies. What could certainly be further developed is the finding in the motivation letter analysis that there is a significant correlation, in the use of the singular by impulsive people irrespective of gender, or the use of a great number of pronouns by extravagant writers (see above).

\section{Conclusion}

As pointed out earlier, personality assessment, in terms of inter- and intrapersonal characteristics, performed via text analysis may prove an interesting and useful tool not just for psychologists but also for specialists working in education and other fields, and researchers and practitioners. Not only is it unobtrusive, as it requires neither the presence of the person examined nor the need for other diagnostic tools, but it also makes it pos- 
sible to gain a deeper understanding of the author of the text, his or her personality, opinions and attitudes. If a database were to be compiled that could show which text characteristic referred to which of the writer's personality traits, it would be possible to process large quantities of text in a fully automatic fashion. Such technique would also enable the researcher to predict the probability of a writer having certain personality traits. The method may be of great use to specialists working with people, such as those who work with pupils or students that are otherwise difficult to deal with and not open to traditional assessment methods. Moreover, the method could be even more effective and precise if it was used in combination with other techniques, such as interview or observation.

To conclude, experimental use of CPA is an interesting method which may result in many promising ideas and research suggestions. If it is explored by researchers, be they linguists, psychologists or educational specialists, it could generate new, potentially unexpected information on human communication, its nature and characteristics.

\section{References}

Aaronson, D., \& Rieber, R. W. (2013). Psycholinguistic research: Implications and applications. Hove: Psychology Press. pp. IX-X.

Austin, J.L. (1975). How to do things with words. Oxford: Oxford University Press.

Campbell, R.S., \& Pennebaker, J.W. (2003). The secret life of pronouns: Flexibility in writing style and physical health. Psychological Science, 14(1), 60-65.

Cegala, D. (1989). A study of selected linguistic components of involvement in interaction. West. J. Speech Communication, 53(3), 311-326.

Cloninger, C.R. (2008). The Psychobiological theory of temperament and character: Comment on Farmer and Goldberg. Psychological Assessment, 20(3), 292-299.

Figurová, L.T. (2007). Sociální desirabilita (Master's Thesis). Masarykova univerzita, Filozofická fakulta. Available from http://is.muni.cz/th/75552/ff_m

Freud, S. (1901). Psychopathology of everyday life. New York: Basic Books.

Furnham, A. (1990). Language and personality. In H. Giles, \& W.H. Robinson (Eds.), Handbook of Language and Social Psychology (pp 73-95), New York: Wiley.

Garside, R., \& Smith, N. (1997). A hybrid grammatical tagger: CLAWS4. In R. Garside, G. Leech, \& A. McEnery (Eds.), Corpus Annotation: Linguistic Information from Computer Text Corpora (pp.102-121). Longman, London.

Hajič, J. (2004). Disambiguation of rich inflection (Comput. Morphology of Czech). Prague: Karolinum.

Hamilton, R.V. (1957). A Psycholinguistic analysis of some interpretive processes of three basic personality types. The Journal of Social Psychology, 46(2), 153-177.

Hornová, L. (2003). Referenčni slouník gramatických terminů. Olomouc: Univerzita Palackého v Olomouci.

Cheng, K.H.C. (2011). Further linguistic markers of personality: The way we say things matters. International Journal of Psychological Studies, 3(1), 2-16. 
Krippendorff, K. (1980). Content analysis: An Introduction to its methodology. Newbury Park, CA: Sage.

Mehl, M.R. (2006). Quantitative text analysis. In M. Eid, \& E. Diener (Eds.), Handbook of multimethod measurement in psychology (pp. 141-156). Washington: American Psychological Association.

Müllner, J., Ruisel, I., \& Farkaš, G. (1980). Príručka pre administráciu, interpretáciu a vyhodnocovanie dotazníka na meranie úzkosti a úzkostlivosti. Bratislava: Psychodiagnostické a didaktické testy.

Nebeská, I. (1992). Úvod do psycholingvistiky. Praha: H\&H.

Oxman, T. E., Rosenberg, S. D., Schnurr, P. P., \& Tucker, G. J. (1988). Diagnostic classification through content analysis of patients' speech. American Journal of Psychiatry, 145(4), 464-468.

Paulhus, D.L. (1988). Assessing self-deception and impression management in self-reports: The Balanced Inventory of Desirable Responding. Unpublished manual, University of British Columbia, Vancouver, Canada.

Pennebaker, J.W., \& Graybeal, A. (2001). Patterns of natural language use: Disclosure, personality, and social integration. Current Directions, 10 (3), 90-93.

Pennebaker, J.W., \& Davis, M. (2006). Pronoun use and dominance. Unpublished data. Department of Psychology, University of Texas at Austin, Austin, TX.

Pennebaker, J.W., \& King, L.A. (1999). Linguistic styles: Language use as an individual difference. Journal of Personality and Social Psychology, 77(6), 1296-1312.

Pennebaker, J.W., Mehl, M.R., \& Niederhoffer, K. (2003). Psychological aspects of natural language use: Our words, our selves. Annual Review of Psychology, 54(1), 547-577. Petkevič, V. (2006). Reliable morphological disambiguation of Czech: Rule-Based approach is necessary. In M. Šimková (Ed.), Insight into the Slovak and Czech Corpus Linguistics (pp. 26-44), Bratislava: Veda.

Preiss, M., Novák, T., Klose, J., Šamánková, D., Březinová, K., \& Štěpánková, H. (2006). Ovlivňování výsledku vyšetření osobnosti: Výsledky dotazníku temperamentu a charakteru. Československá psychologie, 50(3), 251-261.

Rude, S.S., Gortner, E.M., \& Pennebaker, J.W. (2004). Language use of depressed and depression - vulnerable college students. Cognition and Emotion, 18(8), 1121-1133.

Sanford, F.H. (1942). Speech and personality. Psychological Bulletin, 39(10), 811-845. Searle, J. R. (1969). Speech acts: An essay in the philosophy of language. Cambridge: Cambridge University Press.

Shapiro, G., \& Markoff, J. (1997). A Matter of definition. In C. W. Roberts (Ed.), Text analysis for the social sciences: Methods for drawing statistical inferences from texts and transcripts. Mahwah: Lawrence Erlbaum Assoc.

Scherer, K. R., \& Giles, H. (1979). Social markers in speech. Cambridge: Cambridge University Press.

Schnurr, P.P., Rosenberg, S.D., Oxman, T.E., \& Tucker, G.J. (1986). A methodological note on content analysis: Estimates of reliability. Journal of Personality Assessment, 5(4), 601-609.

Spielberger, C.D., Gorsuch, R.L., \& Lushene, R.E. (1970). Manual for the state-trait anxiety inventory. Palo Alto (CA): Consulting Psychologist Press.

Spoustová, D. (2008). Combining statistical and rule-based approaches to morphological tagging of Czech texts. In: Prague Bulletin of Mathematical Linguistics, 89, 23-40. 
Taylor, M.A., Reed, R., \& Berenbaum, S. (1994). Patterns of speech disorders in schizophrenia and mania. Journal of Nerv. and Mental Disease, 182(6), 319-326.

Thomas, C.B., \& Duszynski, K.R. (1985). Are words of the ROR predictors of disease and death? The case of "whirling." Psychosomatic Medicine, 47, 201-211.

Votrubec, J. (2006). Morphological tagging based on averaged perceptron. Praha: WDS'06 Proceedings of Contributed Papers, pp. 191-195.

Weintraub, W. (1989). Verbal behavior in everyday life. New York: Springer.

\section{Authors:}

Dalibor Kučera, Ph.D.

University of South Bohemia in České Budějovice

Faculty of Education

Department of Pedagogy and Psychology

Jeronýmova 10

37115

České Budějovice

Czech Republic

Email: dkucera@pf.jcu.cz

Jana M. Havigerová, Ph.D.

University of Hradec Králové

Faculty of Education

Department of Primary and Preprimary Education

Náměstí svobody 301

50003

Hradec Králové

Czech Republic

Email: jana.havigerova@uhk.cz 